\title{
Smart Card Based Integrated Electronic Health Record System For Clinical Practice
}

\author{
N. Anju Latha*, B. Rama Murthy \\ Department of Electronics \\ Sri Krishnadevaraya University \\ Anantapur, A.P, INDIA
}

\author{
U. Sunitha \\ Department of Electronics \\ Sri Krishnadevaraya University \\ Anantapur, A.P, INDIA
}

\begin{abstract}
Smart cards are used in information technologies as portable integrated devices with data storage and data processing capabilities. As in other fields, smart card use in health systems became popular due to their increased capacity and performance. Smart cards are used as a Electronic Health Record (EHR) Their efficient use with easy and fast data access facilities leads to implementation particularly widespread in hospitals. In this paper, a smart card based Integrated Electronic health Record System is developed. The system uses smart card for personal identification and transfer of health data and provides data communication. In addition to personal information, general health information about the patient is also loaded to patient smart card. Health care providers use smart cards to access data on patient cards. Electronic health records have number of advantages over the paper record, which improve the accuracy, quality of patient care, reduce the cost, efficiency, productivity. In present work we measure the biomedical parameters like Blood Pressure, Diabetes Mellitus and Pulse oxygen measurement.,etc clinical parameters of patient and store health details in Electronic Health record. The system has been successfully tested and implemented (Abstract)
\end{abstract}

Keywords- Electronic health record; Smart card technology; Healthcare using smart cards.

\section{INTRODUCTION}

Automation systems in hospitals serve the purpose of providing an efficient working environment for health care professionals. Access to accurate health data quickly is one of the main functions of this system. There can be many sources that the information related to the patients can be obtained from the patient, test results, doctor diagnoses for patient illness, health measurement devices and previously stored patient information [1]. The usual way of obtaining relevant data is from paper record. The Paper-based records have a low cost and have limitations such as difficult to access, timeconsuming to update, secure, impossible to share and maintain for lifelong.

The problems can be solved by increasing the capabilities of hospital automation systems by using intelligent storage and retrieval mechanism. Smart card can play a key role in sharing patient specific information. The patient can carry the health smart card with him/her anywhere and anytime and present it to the doctor at the time of consultation. Smart cards are more suitable to use in health care information systems because of they are cheap, easy to use, carry and update with new information and should not get damaged easily.
Smart cards can be described as portable integrated devices that store and process data. These tiny computers with their own memories and processors have a widespread usage especially in telecommunication and mass transit systems [2]. Speed, security and portability properties make smart cards a potential tool in healthcare systems. Many countries implement or continue to develop such systems including smart card components. An intensive study on these systems is seen in working projects such as Sesam Vitale in France and DENT card in Germany [3]. Also European Commission supported France-Belgium project Transcards [4], EU IV. Framework R\&D project Netlink [5]. The Health Insurance Card project of Slovenia provides nation-wide use of smart cards in health sector $[6,7]$.

The objective of the present work is to develop a multifunctional user-friendly biomedical measurement device of an Integrated Electronic Health Record System, which provides a complete e-record in place of paper record. The following health parameters are required by any doctor such as Blood Pressure, Blood glucose level measurement, pulse oxygen meter, clinical analyzer. Each device was designed, built, tested and calibrated separately. The modules devices are connected serially to a Personal Computer with a Visual Basic software package. The data acquired from each system is then displayed on the PC monitor and store data in Health Smart card [8].

\section{GeNERAL SPECIFICATIONS}

The system developed is called Integrated Electronic Health Record System (IEHRS).Patients have Health smart cards in IEHRS. Doctors use these cards to access health data with database. Smart cards are used as a mobile health data carrier.

In patient card, personal and patient information is stored. In personal information patient ID, patient's name, surname, birth date, blood type, gender, address and mobile telephone numbers are stored in patient card. Patient health information stored in the card is chronic and/or important former diseases with diagnosis dates, permanently used medications with doses, allergies with diagnosis dates, immunizations with their dates, surgical operations including operation date, clinic name and summary information. Patient's last examination and prescription information are also stored in card [9].

Each Computer has a connected card acceptance devices (CAD) and they can connect to databases. When a doctor 
inserted a card in CAD patient's health data are displayed [10]. After examination, doctor updates inspection and prescription information on patient smart card with new data. Hospital administration unit to record new inspection and prescription data stored on smart card. The hospital administration manage hospital database as well as the other responsibilities of administration is to record new patients to system and to perform smart card related operations like smart card preparation for new users and data update from smart cards to database and database to smart cards[11].

\section{SYSTEM DESCRIPTION- IEHRS BLOCK DIAGRAM \& DESCRIPTION}

The Integrated Electronic Health Record System (IEHRS) block diagram as shown in figure 1 . The primary function of the device is to operate as a medical pre-screening/diagnostic device. The first stage lists the four different types of medical data to be measured by the device. Blood Pressure, Blood Glucose, Pulse Oxymeter and clinical analyzer. In the second stage of the system a Personal Computer reads data from these medical devices and stores it in a specified patient database. In the third stage the stored data is transferred to a health smart card using smart card reader/ writer to create an e-record.the graphical user interface package has developed using Visual Basic for the present work integrated electronic health record system.

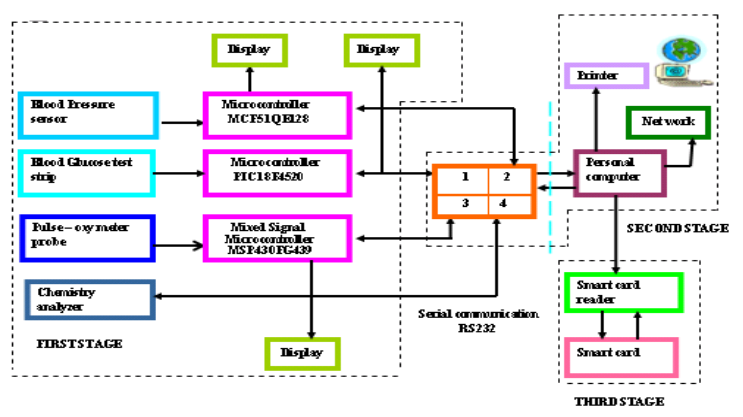

Figure 1: Block Diagram of Integrated Electronic Health Record System

\section{HARDWARE}

\section{A. Blood Pressure Meter}

Blood pressure is the force exerted by circulating blood on the walls of blood vessels. BP is the force created by the heart as it pushes blood into the arteries through the circulatory system. A typical reading will look like " $120 / 80$ " and is measured in mmHg. The upper value is the Systolic Blood Pressure, and the lower value is the Diastolic Blood Pressure.

In the present study, a microcontroller MCF51QE128based system for the measurement of blood pressure is developed. Further, an LCD module to display the data of systolic and diastolic blood pressure and MR2A16A asynchronous magneto resistive RAM to store measured values of systolic diastolic pressure values are interfaced with the microcontroller, which reduces the hardware complexity.

Software is developed in $\mathrm{C}$ language using IAR embedded work bench IDE due to the inherent language flexibility, the extent of support and its potential for portability across a wide range of hardware. The blood pressure measurements were tested and the results are shown in Table 1.

TABLE 1: Measured Blood Pressure values ( $\mathrm{mmHg}$ )

\begin{tabular}{|c|c|c|c|}
\hline $\begin{array}{c}\text { S. } \\
\text { No }\end{array}$ & $\begin{array}{c}\text { Sphygmoma } \\
\text { nometer }\end{array}$ & $\begin{array}{c}\text { Omron } \\
\text { HEM-735C }\end{array}$ & $\begin{array}{c}\text { Present } \\
\text { meter }\end{array}$ \\
\hline 1 & $120 / 80$ & $118 / 78$ & $119 / 79$ \\
2 & $122 / 80$ & $120 / 82$ & $122 / 80$ \\
3 & $130 / 90$ & $128 / 88$ & $129 / 90$ \\
4 & $150 / 90$ & $149 / 89$ & $149 / 92$ \\
5 & $160 / 100$ & $158 / 100$ & $158 / 102$ \\
\hline
\end{tabular}

\section{A. Blood Sugar Level Meter}

Glucose is one of the body's main sources of energy. Diabetes is a chronic metabolic disorder characterized by a high concentration of sugar in the blood. Diabetes mellitus is a condition in which the pancreas no longer produces enough insulin or when cells stop responding to the insulin that is produced, so that glucose in the blood cannot be absorbed into the cells of the body. The body maintains blood glucose levels within a narrow range $(70-130 \mathrm{mg} / \mathrm{dl})$.

In the present design, a microcontroller based system for the measurement of blood glucose is designed and developed. It is based on the Amperometric method. A PIC 18F4520 microcontroller is used in the present study. LCD module is used to display measured values of blood glucose. The MAX232 is a dual line driver/receiver, converts signals form an RS-232 serial port to TTL compatible signals is interfaced with the microcontroller. Software is developed in C language using MPLAB IDE for the Microchip Technology. The blood glucose measurements were tested and the results are shown in Table 2.

TABLE 2: Measured Blood Glucose values (mg/dl)

\begin{tabular}{|c|c|c|c|}
\hline $\begin{array}{c}\text { S } \\
\text { No }\end{array}$ & $\begin{array}{c}\text { One } \\
\text { touch } \\
\text { Ultra 2 }\end{array}$ & $\begin{array}{c}\text { Clinical } \\
\text { Analyzer } \\
\text { RT1904C }\end{array}$ & $\begin{array}{c}\text { Present } \\
\text { meter }\end{array}$ \\
\hline 1 & 136 & 134 & 131 \\
2 & 149 & 148 & 152 \\
3 & 183 & 182 & 180 \\
4 & 315 & 317 & 321 \\
5 & 337 & 332 & 339 \\
\hline
\end{tabular}

\section{B. Oxygen Saturation ( $\mathrm{SaO} 2$ )}

Oxygen saturation level or, $\mathrm{SaO} 2$ reveals the amount of oxygen carried by the blood. A low $\mathrm{SaO} 2$ level can indicate that the body is not getting enough oxygen, and could be a symptom of lung or heart disease. An overly high $\mathrm{SaO} 2$ level can cause oxygen poisoning. Pulse Oxymeter is based on the fractional change in light transmission during an arterial pulse at two different wavelengths.

TABLE 3: Pulse oxygen measurement

\begin{tabular}{|c|c|c|c|c|}
\hline \multirow{2}{*}{$\begin{array}{l}\text { S. } \\
\text { No }\end{array}$} & \multicolumn{2}{|c|}{ BPL Meter } & \multicolumn{2}{c|}{ Present Meter } \\
\cline { 2 - 5 } & $\begin{array}{c}\text { Pulse } \\
\text { oxygen }\end{array}$ & $\begin{array}{c}\text { Pulse } \\
\text { rate }\end{array}$ & $\begin{array}{c}\text { Pulse } \\
\text { Oxygen }\end{array}$ & $\begin{array}{c}\text { Pulse } \\
\text { rate }\end{array}$ \\
\hline 1 & 98 & 68 & 97 & 67 \\
2 & 99 & 68 & 99 & 68 \\
3 & 99 & 70 & 99 & 71 \\
4 & 98 & 67 & 97 & 67 \\
5 & 98 & 69 & 98 & 68 \\
\hline
\end{tabular}


In present design of Pulsoximeter MSP430FG437 microcontrolleris used. The pulsoximeter consists of a peripheral probe combined with the MCU displaying the oxygen saturation and pulse rate on LCD glass. The probe is placed on a peripheral point of the body such as a fingertip, ear lobe or the nose. The probe includes two light emitting diodes (LEDs), one in the visible red spectrum $(660 \mathrm{~nm})$ and the other in the infrared spectrum $(940 \mathrm{~nm})$. The percentage of oxygen in the body is worked by measuring the intensity from each frequency of light after it transmits through the body and then calculating the ratio between these two intensities. The pulse oxygen meter measurements values are tested and the results are shown in Table 3.

The above instruments are tested and results are found to be satisfactory. The instruments are handheld, rugged, low cost, low energy consumption, wearable and cost effective compared to the other commercially available. The measured values are transmitted to a Personal Computer and stored in the patient database to create an e- record

\section{B. Clinical Chemistry Analyzer - RT1904C}

Clinical chemistry analysis is one of the most important areas within clinical laboratory analysis. The term clinical chemistry usually refers to determining the concentration or activity of a protein, carbohydrate, lipid, electrolyte, enzyme or small molecule in easily-collected bodily fluids such as blood, serum, plasma or urine. However, it is not necessarily limited to these determinations. In the present design an RT1904C Clinical Chemistry Analyzer is used and the measurement values of all clinical parameters are transferred to EHR system interfacing with PC through RS-232 with developed IEHRS software package.

\section{SOFTWARE}

In IEHRS we developed exclusive software in Visual Basic for the reading and writing of the health information on to electronic health recording system.

The GUI program in Visual Basic is used to communicate with the medical devices. The code allows us to send and receive characters over RS232 with SQL support for a user database in which the patient data can be stored securely for usage. The patient database could keep track of medical checkup results of patients and are useful in establishing health histories and monitoring trends. Periodically, the database can be uploaded to any specialist for further diagnosis, prevention, and treatment. For example, mild diabetics only require blood sugar level monitoring a few times a week. A database can keep track of their blood sugar history, revealing trends and help develop a plan for controlling their disorder.

When a file is opened it displays the menu bar which consists of six items having individual functions Reader, EHR_Administration, Doctor, Lab and Medical. The Reader option on the menu consists of Connect, Disconnect. The CAD can be connected or disconnected with the computer by selecting the Connect or Disconnect. The option EHR_Administration consists of Registration, admission, discharge, and transfer details of a patient provides vital information for accurate patient identification and assessment, including chief complaint, patient disposition, etc. The personal details contain the personal details, emergency details and insurance details of a patient. The emergency details contain the blood Group, allergies of a patient... etc., The insurance details of a patient consist of a patient insurance policy name, number, policy type, date of issue, date of expiry and amount of patient. The Doctor option consists of Consultation, Discharge Process and Prescription. Laboratory System Components consists of integrate orders, results from laboratory instruments, schedules, billing and other administrative information. In the present work measurement devices like Blood Pressure meter, Blood Glucose meter, Pulseoxy meter and clinical analyzer have been integrated. The measured devices are communicated with the Personal Computer by selecting the serial port. The results are transmitted from the electronic medical device to the Personal Computer. And further it will be transferred to health smart card. Pharmacy System Components consists of the patient's name, number and cost details. The electronic prescribing consists of the drug details of a patient. Flowchart of the system is as shown in fig 2 .

\section{FLOW CHART}

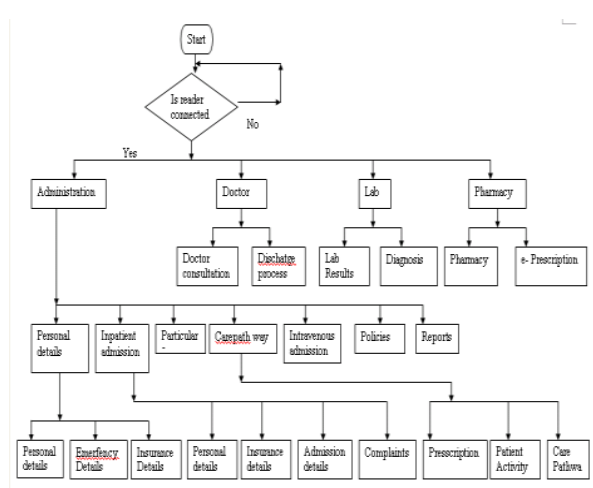

Figure 2: Flow chart of IEHR System

\section{IMPLEMENTATION}

Smart card software is developed in Visual Basic. ACR38 serial card read/write unit is used as CAD in system. It is connected to a terminal PC with 9600 baud data transmission rate. Card terminal interface packages are deployed to a $\mathrm{PC}$ with Intel PIII $650 \mathrm{MHz}$ CPU running MSWindows 2000 operating system. That PC represents a card terminal located in a doctor's room. System administration software is also deployed and tested on this computer.MS SQL Server 2000 is used both for hospital database implementations.

Some performance measurements are also obtained during system tests, containing elapsed time measurement during data transmission between smart card client applications and smart cards. Considering data bus with 9600 baud, to send a command and receive a response with 255 bytes of data and display content in related interface take approximately $1.5 \mathrm{~s}$. To write 255 bytes of data to smart card and receive response from card takes approximately $2 \mathrm{~s}$.

Screenshot in Fig. 3 is taken just after the doctor has accepted a patient and opened a patient session on the clinic application. 
All displayed data (except the remote database message) is received from the patient's smart card. In Fig. 4 patient's medical information about his allergies, diseases, etc., are displayed. The doctor can also access other patient information (e.g. surgical operations, last inspection and prescription) stored on patient's smart card by using the other submenus of the "Patient" menu. The doctor has received her patient's health records according to the distributed object protocol proposed in this paper.

The doctor updates the patient's health records it is enough for her to simply press the "Update" button and approve the operation.

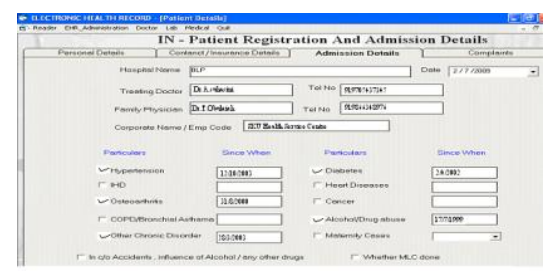

Figure 3: Patient details

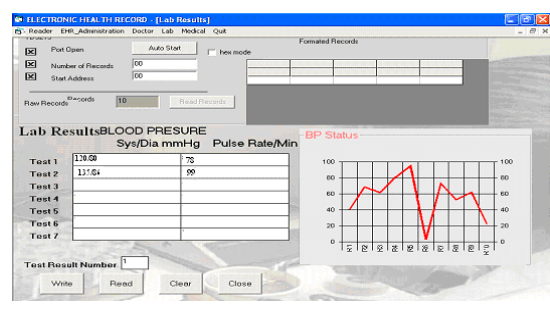

Figure 4: Test results

\section{STATUS REPORT}

IEHRS can be considered as a powerful healthcare automation with integration of smart card use into existing hospital information systems. Its distributed protocol enables mobile and secure access to the patient records and facilitates roles of both healthcare professionals and patients.

However, contribution of smart cards in those studies is limited even in the systems that are currently in use. System has a restricted design in which smart cards only behave as a portable health report card. Potential security and authorization features are not fully presented.

On the other hand, protocol introduced with IEHRS allows use of cards in data storage and but security has to introduced in addition to mobile data carriage.

It should also be noted that architecture of IEHRS takes care of the easy integration of the currently working health information systems in a hospital. Hence, users of the old information system (both health professionals and patients) can adapt to the new system easily and quickly. Finally, it presents electronic prescription data structure with working pharmacy software. Fig 5 shows the electronic prescription format.

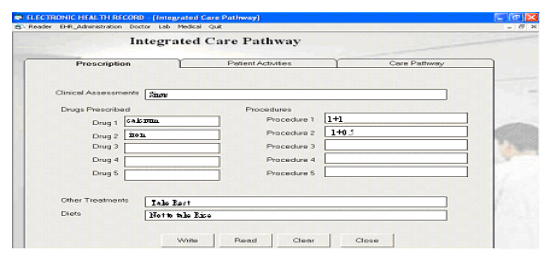

Fig 5: Electronic Prescription window

\section{FUTURE PlanS}

A healthcare automation system based on smart cards is designed and developed. The most important problem encountered during system development is the lack of medical data store and retrieval standardization in healthcare sector. Existence of a worldwide-generic coding standard for healthcare data will surely ease the design and development of smart card based healthcare systems. Our system has its own specific medical data coding in databases. However as standardization occurs, the database can be redesigned to meet those standards. The capacity increase and cheaper costs will improve quality of smart card services.

The present patient cards of the IEHRS can only store last inspection and prescription data. One of our future plans is to integrate smart cards with higher capacity into the system to provide storage of more than one inspection and prescription data on card and simplify the doctor's examination process. With use of such high capacity smart cards, we also intend to store extra medical information like X-ray films and test documents on smart cards.

\section{REFERENCES}

[1]. "Design and implementation of a smart card based healthcare information system", Geylani Kardas, E. Turhan Tunali, journal of Elsevier, computer methods and programs in biomedicine 81 ( 20006 ) 66-78, 2005

[2]. Z. Chen, Java Card TM Technology for Smart Cards Architecture and Programmer's Guide, Addison-Wesley, MA, USA, 2000.

[3]. C. Pagetti, C. Mazini, M. Pierantoni, G. Gualandi, H.Schepel, A European Health Card Final Report, European Parliament, Directorate General for Research, Document for STOA Panel, 2001, pp. 16-29.

[4]. Transcards, GIE Sesam Vitale, Transcards Project, URL: http: //www. esamvitale.fr $/ \mathrm{html} /$ projets/trans cards / tcd accueil eng.htm, last accessed: 2002.

[5]. Netlink, GIE Sesam Vitale, Netlink Project, URL:http:// www.sesamvitale.fr/ html /projets/netlink/index.htm, last accessed: 2002

[6]. R. Novak, G. Kandus, D. Trcek, Further development of a smart-card based health care information system in Slovenia, in: Presented at the Fifth International Congress on Conference and Exhibition on Cards Applications in Health Care: Health Cards'99, Milan, Italy, 1999.

[7]. R. Novak, G. Kandus, D. Trcek, Slovene smart-card and IP based health-care information system infrastructure, in: International Journal of Medical Informatics, vol. 61, Elsevier, 2001, pp. 33-43.

[8]. "Smart cards applications in the Healthcare Systems", claudiu oltean, Journal of Mobile, Embedded and Distributed Systems.

[9]. "Health Care Implementation by Means of Smart Cards", ,Dr. Magdy E. Elhen nawy, Dr. M. Amer, A. Abdelhafeez, International Journal of Computer Science Issues, Vol. 8, Issue 1, January 2011 ISSN (Online): 1694-0814 www.IJCSI.org 
[10]. "Health Smart Home", Ahmad CHOUKEIR, Batoul FNEISH , Nour ZAAROUR, Walid FAHS , Mohammad AYACHE IJCSI International Journal of Computer Science Issues, Vol. 7, Issue 6, November 2010, ISSN : 1694- 0814.

[11]. Alvin T. S. Chan, "smart card: towards a mobile health care management system", International Journal of Medical Informatics, Elsevier Science Ireland Ltd, Volume 57, Issues 2-3, Pages 127-137, July 2000.

\section{AUTHORS PROFILE}

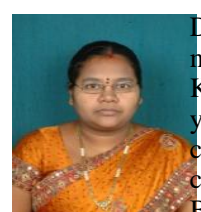

D. N. Anju latha presently working as teaching faculty nember in thd department of Instrumentation and USIC, Sri Krishnadevaraya University, Anantapur. She is having three years Industrial experience as $\mathrm{R} \& \mathrm{D}$ Engineer in onceptualization and development of Micro ontroller/Microprocessor-based products and solutions for Cards based devices.

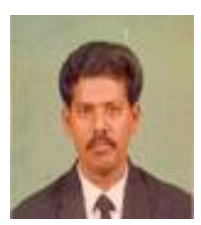

Dr.B.RamaMurthy is presently working as a Professor in the Department of Instrumentation \& USIC, Sri Krishnadevaraya University, Anantapur, Andhra Pradesh, India. He is having 20 years of Research \& teaching experience. Under His guidance 8 Ph.D \& 4 M.Phils are awarded. His areas of interest are Embedded Systems, Network and Mobile Communications, network security systems, Industrial and Bio-medical Instrumentation.

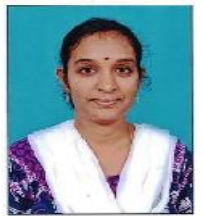

U.Suneetha is doing P.hd in the Department of Electronics and communications, Sri Krishna Devaraya university, Anantapur. She also working as a Teaching assistant in the Department of Electronics and communications, Sri Krishna Devaraya university, anantapur, Andhrapradesh, India. She having nine years of teaching experience. Her area of interest are Wireless communications and embedded systems 